$\mathrm{DE}$

M E D I C I N A

T R O P I C A L

$\mathrm{DE}$

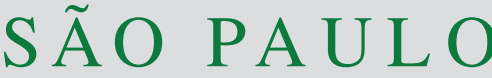

JOURNAL OF THE SÃO PAULO INSTITUTE OF TROPICAL MEDICINE

1Universidade Paulista, Instituto de Ciências da Saúde, Ribeirão Preto, São Paulo, Brazi

2Universidade de São Paulo, Faculdade de Medicina de Ribeirão Preto, Departamento de Biologia Celular e Molecular, Ribeirão Preto, São Paulo, Brazil

${ }^{3}$ Universidade Estadual de Campinas, Instituto de Biologia, Campinas, São Paulo, Brazil

${ }^{4}$ Universidade de São Paulo, Faculdade de Filosofia, Ciências e Letras de Ribeirão Preto, Departamento de Biologia, Ribeirão Preto, São Paulo, Brazil

Correspondence to: Ademilson PanuntoCastelo

Universidade de São Paulo, Faculdade de Filosofia, Ciências e Letras de Ribeirão Preto, Departamento de Biologia, Av. Bandeirantes, 3900, CEP 14040-901 Ribeirão Preto, SP, Brazil

E-mail: apcastelo@usp.br

Received: 20 December 2019

Accepted: 12 March 2020

\section{Expression of Hsp60 and its cell location in Paracoccidioides brasiliensis}

Fabrício Freitas Fernandes ${ }^{1,2}$, Nayla S. Pitangui ${ }^{2}$, Gabriela Peron ${ }^{3}$, Clarissa X. R. Valim², Vívian M. Mazucato², Aline F. Oliveira ${ }^{1,2}$, Thiago A. da Silva², MariaCristina Roque-Barreira ${ }^{2}$, Ademilson Panunto-Castelo ${ }^{(14}$

\section{ABSTRACT}

Paracoccidioides species cause paracoccidioidomycosis (PCM), a systemic mycosis highly prevalent in Brazil. Therapy of PCM has some issues that make studies for new therapeutic and vaccine targets relevant, such as the $P$. brasiliensis $60-\mathrm{kDa}$-heat-shock protein ( $\mathrm{PbHsp60)}$, an immunogenic antigen that induces protection in experimental mice infection. Here, we investigated the relative expression of mRNA for $\mathrm{PbHsp60} \mathrm{in} \mathrm{P.} \mathrm{brasiliensis} \mathrm{in} \mathrm{the}$ different morphotypes of $P$. brasiliensis and in morphological transition phases. In addition, antibodies to $\mathrm{rPbHsp60}$ were produced and used to analyze the location of PbHsp60 in yeast and hyphae by electron microscopy. The analyses showed a substantial increase in the relative amounts of $H S P 60 \mathrm{mRNA}$ in yeast when compared to mycelium and an intermediate expression in transitional forms. Regarding the cell location, immunoelectron microscopy analysis revealed that $\mathrm{PbHsp60}$ is within the cell wall. These observations suggest that this protein may be involved in the maintenance of the cell wall integrity and the interaction with the host for colonization, infection and pathogenesis.

KEYWORDS: Paracoccidioides brasiliensis. Heat-shock proteins. Hsp60. Subcellular localization.

\section{INTRODUCTION}

Besides Paracoccidioides brasiliensis and P. lutzii, which are undoubtedly recognized causative agents of paracoccidioidomycosis (PCM), Turissini et al. ${ }^{1}$ have recently proposed to elevate three cryptic phylogenetic species to taxonomic species - PS2 for P. americana, PS3 for P. restrepiensis, and PS4 for P. venezuelensis. PCM is an endemic systemic mycosis in Latin America and highly prevalent in Brazil, where it is the leading cause of mortality among systemic mycoses and the eighth cause of deaths among chronic infectious diseases. In Brazil, about $49 \%$ of systemic mycoses were associated with PCM in the period between 1998 and 2006 2,3.

Cellular components from Paracoccidioides spp. have been widely studied as inducers of protective cellular immune response. Some of these components are immunogenic antigens that have been considered for the development of an alternative immunotherapeutic method, such as gp43 and its P10 peptide ${ }^{4,5}$ and the heat shock protein $60(\mathrm{Hsp} 60)^{6,7}$. Hsp60 has been successfully explored as a potential immunoprotective antigen against infections caused by $P$. brasiliensis and $P$. lutzii $i i^{6,8}$.

Regarding the fungal biology, Hsps have a prominent role, especially in dimorphic fungi, and are produced in response to shifts of temperature and $\mathrm{pH}$, antifungal and oxidative stress, starvation and osmotic stress ${ }^{9}$. Additionally, Hsps 
have been implicated in cell protection, protein translocation across cellular membranes (chaperones), growth and differentiation of cells ${ }^{10}$. Different researchers have focused their analysis on Hsp60 from P. brasiliensis and $P$. lutzii ${ }^{6-8,10}$. Izacc et al. ${ }^{10}$ showed higher Hsp60 expression in $P$. brasiliensis yeast cells than in mycelium by twodimensional gel electrophoresis analysis. These authors suggest an essential role of this protein in the survival of fungi at host temperature. Furthermore, the authors showed increased Hsp60 expression during the transition from mycelium to yeast and decreased expression during the conversion to mycelium, i.e., Hsp60 appears to have a crucial role in Paracoccidioides morphogenesis ${ }^{10}$.

Here, we quantified the heat-regulated HSP 60 mRNA relative expression in the different morphotypes (mycelium and yeast) and morphological transition phases (myceliumto-yeast and yeast-to-mycelium) of P. brasiliensis. Moreover, we determined the cellular location of the Hsp60 protein in $P$. brasiliensis cell wall in mycelium and yeast morphotypes.

\section{MATERIALS AND METHODS}

\section{Mice and ethics statement}

Male BALB/c mice, 6-8 weeks old, weighing 20-25 g $(\mathrm{n}=5$ /group) were obtained from the Animal Facility of University of Sao Paulo (USP) at Ribeirao Preto campus and maintained at the Animal House of Ribeirao Preto Medical School, USP. This study was performed following the ethical principles of animal research adopted by the Brazilian Society of Laboratory Animal Science and was approved by the Ethics Committee on Animal Use of the Ribeirao Preto Medical School, USP (protocol $\left.\mathrm{N}^{\mathrm{o}} 146 / 2007\right)$.

\section{$P$. brasiliensis culture}

Yeast cells of $P$. brasiliensis strain 18 (Pb18) were cultured at $37^{\circ} \mathrm{C}$ in Dulbecco's Modified Eagle Medium (DMEM; Sigma-Aldrich, St Louis, USA), under stirring at $100 \mathrm{rpm}$. Studies with the different morphological and transition phases were performed as described previously ${ }^{11}$. Briefly, yeast cells and mycelial forms were cultured at $37{ }^{\circ} \mathrm{C}$ and $25{ }^{\circ} \mathrm{C}$, respectively, for at least 7 days. The transition phase from mycelium-to-yeast was induced by culturing the mycelia at $37{ }^{\circ} \mathrm{C}$ for $24 \mathrm{~h}$. The transition from yeast-to-mycelium was obtained by growing yeast at $25^{\circ} \mathrm{C}$ for $24 \mathrm{~h}$. One aliquot of each $P$. brasiliensis culture was analyzed by optical microscopy to verify the fungal morphology.

\section{Differential expression of HSP60 mRNA in $P$. brasiliensis}

The HSP60 gene expression profile in the different morphological and transition phases of $P$. brasiliensis was analyzed by real-time PCR (qPCR). The total RNA from the P. brasiliensis was extracted using TRIzol (Thermo Fisher Scientific, Waltham, USA) as described previously ${ }^{11}$. First-strand cDNA was synthesized using $1 \mu \mathrm{g}$ of total RNA with oligo (dT)12-18 primers (Thermo Fisher Scientific, Waltham, USA) and SuperScript III reverse transcriptase (Thermo Fisher Scientific). Real-time PCR was performed using the Kit Platinum SYBR Green qPCR SuperMix-UDG with ROX (Thermo Fisher Scientific, Waltham, USA), according to the manufacturer's instructions. Specific primers were used for the HSP60 gene: 5'-GATACCAAGGCGCAGAAGGT-3' (sense) and 5'-GGTGAAAACAGT GGCGTTGG-3' (antisense). Fold changes in mRNA expression were calculated using the $2^{-\Delta \mathrm{Cq}}$ formula, where $\Delta \mathrm{Cq}$ is the difference in the threshold cycle (Cq) between the Hsp60 (target) gene and the $\beta$-actin or $\alpha$-tubulin reference genes. The primer sequence of the $\beta$-actin and $\alpha$-tubulin genes were: 5'-GGATGAGGAGATGGATTATGG-3' (sense) and 5'-GA AACACTCGACGCACACGAC-3' (antisense); and 5'-GTGGACCAGGTGATCGATGT-3' (sense) and 5'-ACCCTGGAGGCAGTCACA-3' (antisense), respectively.

\section{Production of anti-rPbHsp60 antibody}

Recombinant $\mathrm{PbHsp} 60$ ( $\mathrm{rPbHsp} 60$ ) was obtained from pET28a-HSP60 vector-transformed Escherichia coli, as described previously. ${ }^{7}$ Protein concentration was determined using the Pierce Coomassie Plus (Bradford) assay kit (Thermo Fisher Scientific) and the preparation homogeneity was analyzed by $12 \%$ sodium dodecyl sulfatepolyacrylamide gel electrophoresis (SDS-PAGE) using a Mini-Protean Tetra System (Bio-Rad, Hercules, CA, USA). Protein bands were excised and homogenized in phosphate-buffered saline, $\mathrm{pH} 7.2$ (PBS), in a concentration of about $200 \mu \mathrm{g} / \mathrm{mL}$, and emulsified in an equal volume of complete (CFA) or incomplete (IFA) Freund's adjuvant (Sigma-Aldrich). BALB/c mice were initially injected subcutaneously with $100 \mu \mathrm{L}$ of antigen-CFA emulsion and afterward weekly with a booster of $100 \mu \mathrm{L}$ of antigen-IFA emulsion. One week after the third boost, mice were bled and the sera containing polyclonal anti-rPbHsp60 antibodies were pooled and stored at $-20^{\circ} \mathrm{C}$. Pre-immune sera were collected, pooled and used as the experiment control. 


\section{Preparation of total soluble antigens from P. brasiliensis}

Yeast cells cultured as described above were washed with PBS by centrifugation at $7,000 \times g$ at $4{ }^{\circ} \mathrm{C}$ for $10 \mathrm{~min}$, resuspended in PBS and disrupted by ten sonication cycles on ice, each consisting of 1-min sonication at $200 \mathrm{~W}$ with 1 -min resting interval. The supernatant from the sonicated sample, which was centrifuged at $7,000 \times g$ at $4{ }^{\circ} \mathrm{C}$ for $10 \mathrm{~min}$, was filtered (PbAgs) and analyzed by $12 \%$ SDS-PAGE.

\section{Western Blotting}

Following the electrophoresis, separated bands were transferred to polyvinylidene fluoride membranes (Hybond membranes Amersham Hybond P 0.45 PVDF, GE Healthcare, Little Chalfont, UK) at $150 \mathrm{~V}$ for $2 \mathrm{~h}$. Membranes were blocked for $2 \mathrm{~h}$ at $25^{\circ} \mathrm{C}$ in $3 \%$ bovine serum albumin (BSA) in TTBS (0.1\% Tween-20, $20 \mathrm{mM}$ Tris- $\mathrm{HCl}, 150 \mathrm{mM} \mathrm{NaCl}, \mathrm{pH}$ 7.6), and incubated overnight at $4{ }^{\circ} \mathrm{C}$ with anti-rPbHsp60 polyclonal antibody at 1:3,000 dilution in $1 \%$ BSA in TTBS. Then, membranes were washed five times with TTBS and incubated for $2 \mathrm{~h}$ at $25^{\circ} \mathrm{C}$ with an anti-mouse secondary antibody $\operatorname{IgG}$ conjugated to peroxidase (Sigma-Aldrich) at 1:3,000 dilution in 1\% BSA in TTBS. Blots were washed as described above and immersed in ECL reagent for 1 minute for the detection of protein using a ChemiDoc MP Imaging System (Bio-Rad).

\section{Immunoelectron microscopy}

Mycelium and yeast cells of $P$. brasiliensis were cultured in DMEM (Sigma-Aldrich) at $25^{\circ} \mathrm{C}$ and $37^{\circ} \mathrm{C}$, respectively, for 7 days. The cells were washed with PBS and fixed in $3.7 \%$ formaldehyde buffered with PBS at $25{ }^{\circ} \mathrm{C}$ for $1 \mathrm{~h}$. Then, the cells were rinsed with PBS and resuspended in $0.05 \%$ glutaraldehyde buffered with PBS and incubated at $25{ }^{\circ} \mathrm{C}$ for $15 \mathrm{~min}$. In the next step the cells were washed three times with PBS and resuspended in PBS containing $0.1 \%$ Triton $\mathrm{X}-100$ and incubated at $25{ }^{\circ} \mathrm{C}$ for $45 \mathrm{~min}$. The samples were recovered and washed with $1 \mathrm{~mL}$ of PBS. Cells were incubated with $1 \mathrm{~mL}$ PBS containing $1 \%$ BSA (PBS-BSA) at $25^{\circ} \mathrm{C}$. After $1 \mathrm{~h}$, pre-immune serum or anti-Pb-Hsp60 polyclonal antibody (1:1000) was added for $1 \mathrm{~h}$ at $25^{\circ} \mathrm{C}$. After washing with PBS-BSA, colloidal gold-conjugated anti-mouse IgG (Nanoprobes Inc., NY, USA) was added to the cells for $1 \mathrm{~h}$ at $25^{\circ} \mathrm{C}$. The cells were washed five times with PBS, with 5 min of incubation for each wash and fixed with $2.5 \%$ glutaraldehyde in $100 \mathrm{mM}$ cacodylate buffer (pH 7.4) (EM Sciences, Hatfield, USA) at $25{ }^{\circ} \mathrm{C}$ for $1 \mathrm{~h}$. Cells were washed with cacodylate buffer and incubated at $4{ }^{\circ} \mathrm{C}$ for $18 \mathrm{~h}$, followed by washing five times with ultrapure water. Further processing of cells was performed as per manufacturer's instructions of Gold Enhancement (Nanoprobes). Subsequently, the cells samples were prepared to electron microscopy as described previously ${ }^{11}$. Finally, the sections were observed with a transmission electron microscope Jeol JEM-100 CXII (JEOL, Peabody, MA, USA).

\section{Statistical analysis}

The differences among means of the differential expression of the HSP 60 mRNA in the different morphologies and transition phases were defined using a one-way analysis of variance followed by Bonferroni's posttest. Differences were recognized as statistically significant at $\mathrm{P}<0.05$. All the experiments were repeated at least twice.

\section{RESULTS AND DISCUSSION}

Dimorphism is an adaptive mechanism of some fungi that grow saprophytically in ambient temperature and are able to adjust to the higher temperatures of their hosts. This ability has been driven many authors to search for the main virulence factors that correlate pathogenicity with the morphological transition ${ }^{9}$. The effect of temperature on the gene expression profile in several fungi is remarkable, among which we highlight the one of HSP60, which increases its expression in a temperature-dependent manner ${ }^{12}$.

In the current study, we evaluated the HSP60 mRNA expression in yeast and hyphal forms of $P$. brasiliensis as well as in their transition forms using qRT-PCR. $P$. brasiliensis was cultured at different temperatures to obtain yeasts, hyphae and transitional forms (mycelium-toyeast and yeast-to-mycelium). These forms of $P$. brasiliensis were observed in light microscopy, and both mycelia and yeasts had the expected morphotypes. Moreover, the mycelium-to-yeast transitional phase had chlamydosporelike intercalary and terminal cells, and yeast-to-mycelium transition had cells with elongation (Figures 1A-1D), as already described ${ }^{13}$. The measurement of HSP60 mRNA of mycelium and yeast of $P$. brasiliensis showed higher levels of expression of HSP6O in yeast forms than those of mycelium (Figure 1E).

Interestingly, the mycelium-to-yeast transition form had increased the levels of relative expression of HSP6O compared to the yeast-to-mycelium transition form (Figure 1E). A previous study suggested that fever can activate the HSP6O gene expression in the host and subsequently modify the immunoregulatory process ${ }^{14}$. 

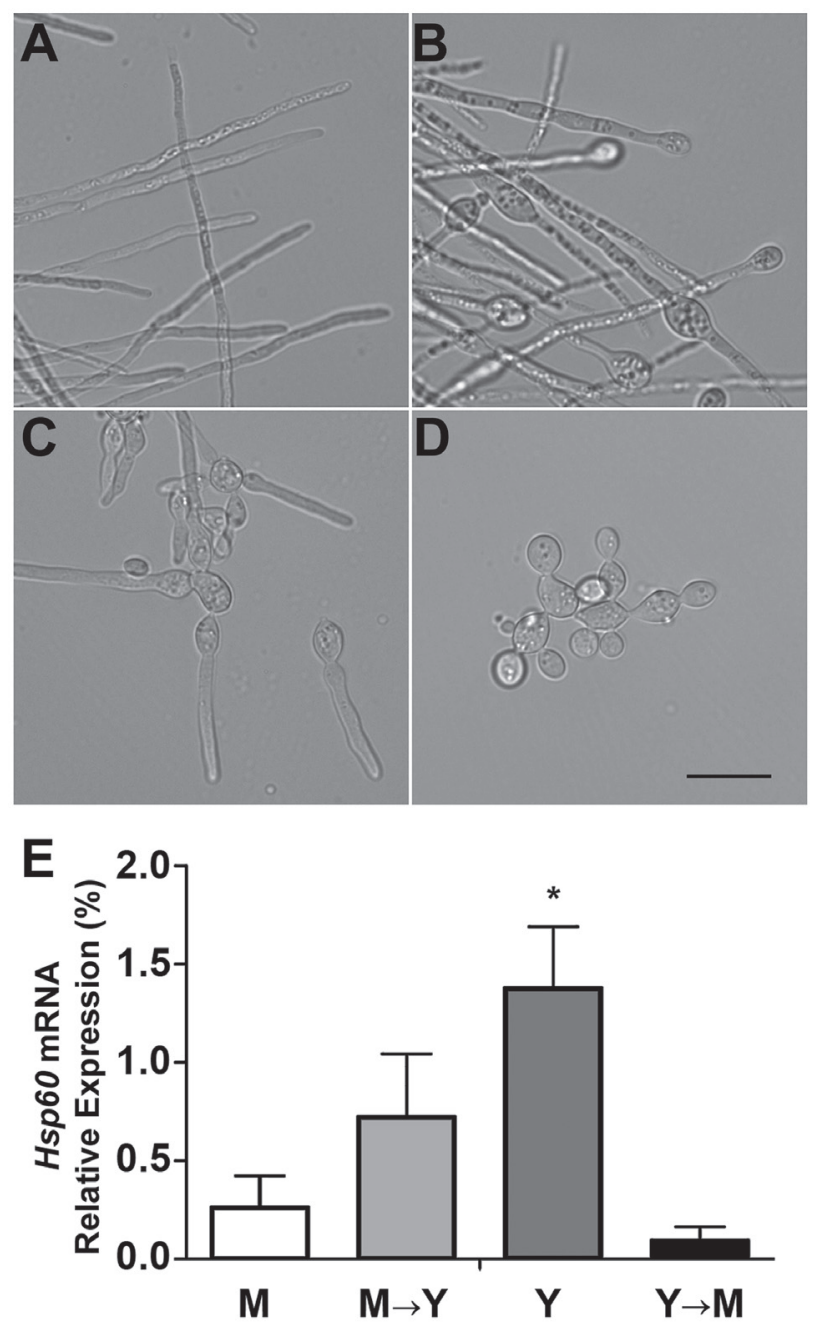

Figure 1 - Differential expression of the HSP60 mRNA in the different morphologies and transition phases of $P$. brasiliensis. Optical microscopy of mycelia (A), mycelia-to-yeast (B), yeast-to-mycelia (C), yeast (D) of $P$. brasiliensis. The bars correspond to $10 \mu \mathrm{m}$. (E) Differential expression of HSP6O mRNA in the different morphologies and transition phases performed by $\mathrm{qPCR}$. The abbreviation $M$ refers to mycelia, $\mathrm{M} \rightarrow \mathrm{Y}$, mycelia-to-yeast, $\mathrm{Y}$, yeast, and $\mathrm{Y} \rightarrow \mathrm{M}$, yeast-to-mycelia. Data are expressed as the mean \pm standard deviation of five samples per group. ${ }^{*} P<0.05$ compared to the mycelia and yeast-to-mycelia groups.

These findings support that the temperature of $37{ }^{\circ} \mathrm{C}$ is critical for regulating the expression of HSP6O in $P$. brasiliensis. Therefore, new roles that Hsp60 plays in the lifestyle of $P$. brasiliensis should be investigated.

The H. capsulatum Hsp60, which has high identity with $P$. brasiliensis $\mathrm{Hsp} 60^{15}$, is located on the yeast cell surface and is recognized by CD18/CD11b expressed in macrophages ${ }^{16}$. In general, the interaction between components of fungal cell walls and receptors of innate immune cells should be explored due to the effects on the regulation of the host immune respons $\mathrm{e}^{17}$. Besides, Holbrook and Rappleye ${ }^{18}$ suggested that Hsp60 is an

H. capsulatum adhesin that interacts with the CR3 molecule on phagocytes. These findings instigated us to investigate the cell location of PbHsp60 in yeast and mycelial forms. rPbHsp60 was expressed in E. coli, purified using HisTap column (Figure 2A), and used to immunize mice. An anti$\mathrm{PbHsp} 60$ murine polyclonal antibody pAb-PbHsp60 was obtained, and it revealed only a protein band on Western blotting even when it was used in a preparation with multiples $P$. brasiliensis somatic antigens (Figure 2B). When the pAb-PbHsp60 was also used to identify the cell location of PbHsp60 in yeast and mycelial forms of P. brasiliensis by immunoelectron microscopy, we found that Hsp60 was located in the cytoplasm and within the fungal cell wall, where it had a prominent distribution on yeasts when compared with hyphae (Figure 3).

A
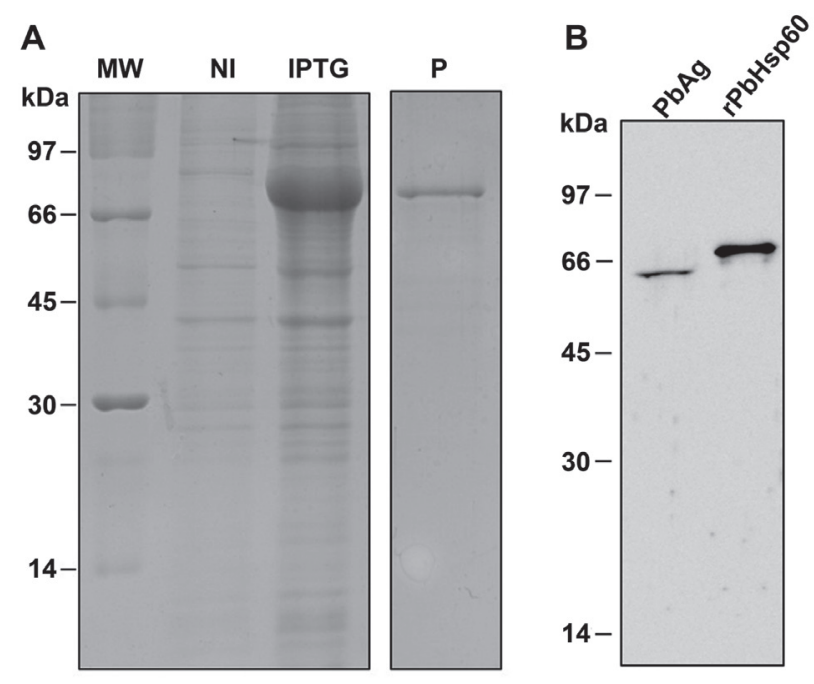

Figure 2 - Expression of rPbHsp60 in P. brasiliensis and analysis of the reactivity with anti-rPbHsp60 polyclonal serum: A) pET28a-HSP60-transformed E. coli were cultured in LB broth in the absence (NI) or presence (IPTG) of the inductor of the recombinant protein for $6 \mathrm{~h}$ at $37^{\circ} \mathrm{C}$ under constant agitation. The recombinant protein was purified $(P)$ on a HisTrap column. The preparations were analyzed in an SDS-PAGE and the proteins visualized by staining with Coomassie brilliant blue G250 (USB Corporation, Cleveland, OH, USA); B) Whole soluble antigens $(\mathrm{PbAg})$ and recombinant protein ( $\mathrm{rPBHsp60})$ were separated by $12 \%$ SDS-PAGE, blotted blotted onto a PVDF membrane and probed with an anti-rPbHsp60 polyclonal antibody. The antigen-antibody reactions were revealed with the ECL reagent.

In summary, the current study showed the prevalence of Hsp60 expression in yeast and mycelium-to-yeast transition forms and identified it within the cell wall, which is critical in the host-pathogen interaction, and in this way, Hsp60 is a potential target to be explored from the therapeutic point of view. Our findings open perspectives to better understand the importance of Hsp60 for the lifestyle of $P$. brasiliensis, allowing for new approaches immunotherapy against PCM. 

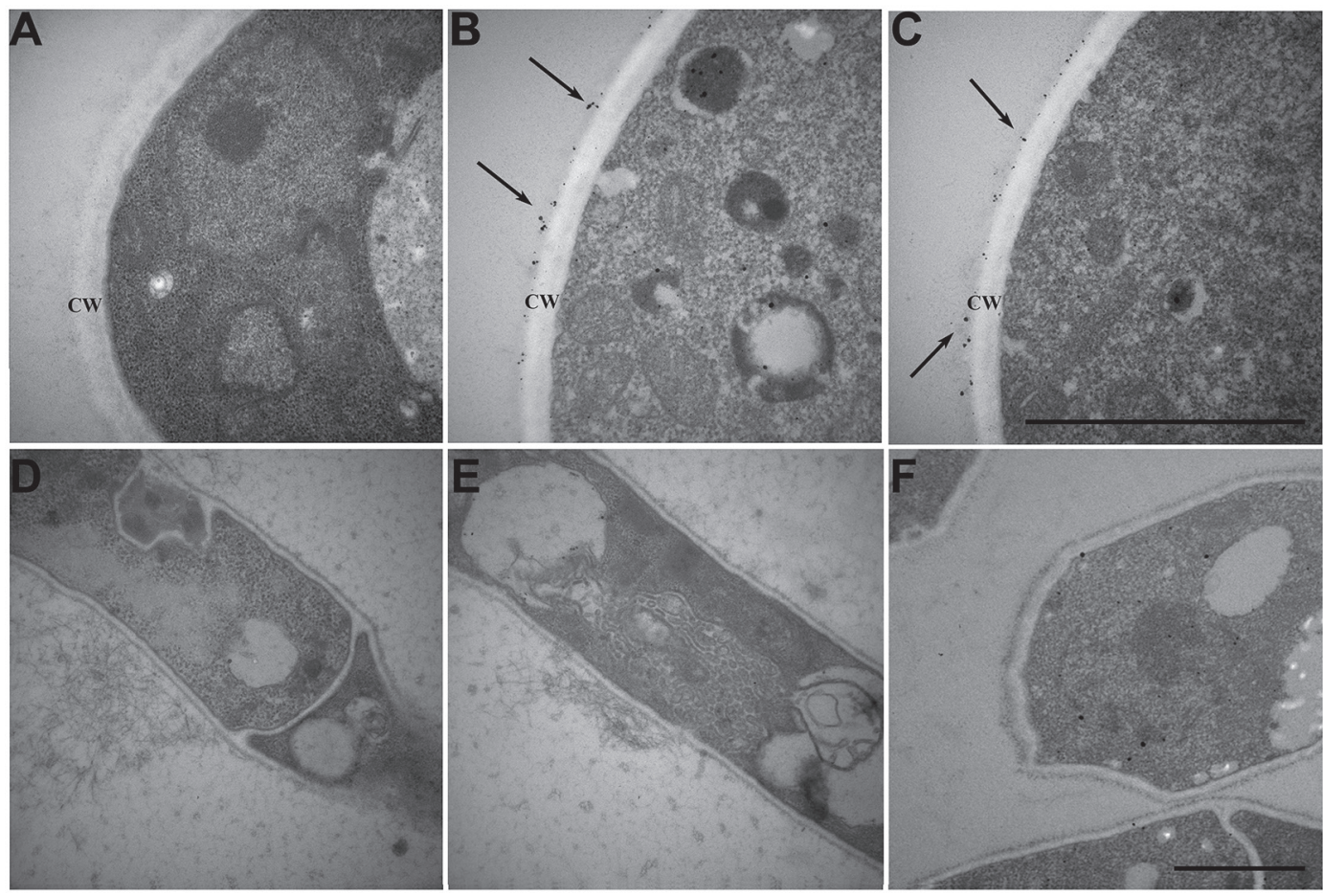

Figure 3 - Subcellular location of Hsp60 at $P$. brasiliensis by immunoelectron microscopy. (A-C) Yeast cells and (D-F) mycelium of $P$. brasiliensis were cultured in DMEM at $37^{\circ} \mathrm{C}$ and $25^{\circ} \mathrm{C}$, respectively, for 7 days. Samples were fixed and incubated with $(\mathrm{A}$ and $\mathrm{D})$ pre-immune serum or (B, C, E and F) anti-rPbHsp60 polyclonal antibody. The arrows show the PbHsp60 within the cell wall (CW) of $P$. brasiliensis. Scale bar $=2 \mu \mathrm{m}$.

\section{ACKNOWLEDGMENTS}

We thank Maria Dolores Seabra Ferreira, José Augusto Maulin, and Thalita Riul Prado Gonçalves for technical support. Supported by Fundação de Amparo à Pesquisa do Estado de São Paulo (grants No 2016/00629-4 and $\mathrm{N}^{\circ}$ 2017/01390-8) and Conselho Nacional de Desenvolvimento Científico e Tecnológico - CNPq (grant $\left.\mathrm{N}^{\circ} 150036 / 2014-0\right)$. The funders had no role in study design, data collection, and analysis, decision to publish, or preparation of the manuscript.

\section{CONFLICT OF INTERESTS}

On behalf of all of the authors, the corresponding author states that there is no conflict of interests.

\section{REFERENCES}

1. Turissini DA, Gomez OM, Teixeira MM, McEwen JG, Matute DR. Species boundaries in the human pathogen Paracoccidioides. Fungal Genet Biol. 2017;106:9-25.

2. Coutinho ZF, Wanke B, Travassos C, Oliveira RM, Xavier DR, Coimbra Jr CE. Hospital morbidity due to paracoccidioidomycosis in Brazil (1998-2006). Trop Med Int Health. 2015;20:673-80.
3. Dutra LM, Silva TH, Falqueto A, Peçanha PM, Souza LR, Gonçalves SS, et al. Oral paracoccidioidomycosis in a singlecenter retrospective analysis from a Brazilian southeastern population. J Infect Public Health. 2018;11:530-3.

4. Muñoz JE, Luft VD, Amorim J, Magalhães A, Thomaz L, Nosanchuk JD, et al. Immunization with P10 peptide increases specific immunity and protects immunosuppressed BALB/c mice infected with virulent yeasts of Paracoccidioides brasiliensis. Mycopathologia. 2014;178:177-88.

5. Taborda CP, Juliano MA, Puccia R, Franco M, Travassos LR. Mapping of the T-cell epitope in the major 43-kilodalton glycoprotein of Paracoccidioides brasiliensis which induces a Th-1 response protective against fungal infection in BALB/c mice. Infect Immun. 1998;66:786-93.

6. Soares RB, Gomez FJ, Soares CM, Deepe GS. Vaccination with heat shock protein 60 induces a protective immune response against experimental Paracoccidioides brasiliensis pulmonary infection. Infect Immun. 2008;76:4214-21.

7. Fernandes FF, Oliveira LL, Landgraf TN, Peron G, Costa MV, Coelho-Castelo AA, et al. Detrimental effect of fungal 60-kDa heat shock protein on experimental Paracoccidioides brasiliensis infection. PloS One. 2016;11:e0162486.

8. Thomaz L, Nosanchuk JD, Rossi DC, Travassos LR, Taborda CP. Monoclonal antibodies to heat shock protein 60 induce a protective immune response against experimental Paracoccidioides lutzii. Microbes Infect. 2014;16:788-95. 
9. Rappleye CA, Goldman WE. Defining virulence genes in the dimorphic fungi. Annu Rev Microbiol. 2006;60:281-303.

10. Izacc SM, Gomez FJ, Jesuino RS, Fonseca CA, Felipe MS, Deepe GS, et al. Molecular cloning, characterization and expression of the heat shock protein 60 gene from the human pathogenic fungus Paracoccidioides brasiliensis. Med Mycol. 2001;39:445-55.

11. Landgraf TN, Costa MV, Oliveira AF, Ribeiro WC, Panunto-Castelo A, Fernandes FF. Involvement of dihydrolipoyl dehydrogenase in the phagocytosis and killing of Paracoccidioides brasiliensis by macrophages. Front Microbiol. 2017;8:1803.

12. Raggam RB, Salzer HJ, Marth E, Heiling B, Paulitsch AH, Buzina W. Molecular detection and characterisation of fungal heat shock protein 60. Mycoses. 2011;54:e394-9.

13. San-Blas F, San-Blas G. Paracoccidioides brasiliensis. In: Szaniszlo PJ, editor. Fungal dimorphism: with emphasis on fungi pathogenic for humans. New York: Plenum; 1985. p.93120

14. Sonna LA, Hawkins L, Lissauer ME, Maldeis P, Towns M, Johnson SB, et al. Core temperature correlates with expression of selected stress and immunomodulatory genes in febrile patients with sepsis and noninfectious SIRS. Cell Stress Chaperones. 2010;15:55-66.

15. Peron G, Fernandes FF, Landgraf TN, Martinez R, PanuntoCastelo A. Recombinant $60-\mathrm{kDa}$ heat shock protein from Paracoccidioides brasiliensis: is it a good antigen for serological diagnosis of paracoccidioidomycosis? Braz J Med Biol Res. 2017;50:e5928.

16. Long KH, Gomez FJ, Morris RE, Newman SL. Identification of heat shock protein 60 as the ligand on Histoplasma capsulatum that mediates binding to $\mathrm{CD} 18$ receptors on human macrophages. J Immunol. 2003;170:487-94.

17. Siqueira KZ, Campos Soares AM, Dias-Melicio LA, Calvi SA, Peracoli MT. Interleukin-6 treatment enhances human monocyte permissiveness for Paracoccidioides brasiliensis growth by modulating cytokine production. Med Mycol. 2009;47:259-67.

18. Holbrook ED, Rappleye CA. Histoplasma capsulatum pathogenesis: making a lifestyle switch. Curr Opin Microbiol. 2008;11:318-24. 